\title{
REPERTÓRIOS MODERNOS
}

MODERN REPERTOIRES

\section{DUDEQUE, MARCO CEZAR}

Doutor, Universidade Federal do Paraná, marcodudeque@gmail.com

\section{WEIHERMANN, SILVANA}

Doutora, Universidade Federal do Paraná, Silvana.w@ufpr.br

\section{RESUMO}

Este artigo foi elaborado a partir de atividades planejadas para a disciplina de 'Estudos da Forma', presente no $1^{\circ}$ ano do curso de Arquitetura da UFPR, trabalho que buscou colaborar com a construção de um repertório arquitetônico que servisse de base para a futura experimentação em projeto, nos anos seguintes do curso. Foram elencados três arquitetos da primeira geração da arquitetura moderna, na seguinte ordem: Mies van der Rohe, Le Corbusier e Alvar Aalto. Tal sequência se justificou baseada no grau evolutivo de complexidade de linguagem de cada arquiteto. O trabalho se desenvolveu inicialmente com o estudo e a discussão sobre as obras de excelência de cada arquiteto em seminário. Posteriormente se deu a construção de maquetes de papelão que deveriam representar espaços de contemplação e passagem, sem uso específico.

PALAVRAS-CHAVE: arquitetura moderna; estratégias compositivas; ensino de projeto.

\section{ABSTRACT}

This article was prepared from planned activities for the discipline 'design studies', present in the 1st year of Architecture course of UFPR. This study sought to collaborate with the construction of an architectural repertoire that would serve as a basis for further experimentation in design, from the following course years. They were listed three architects of the first generation of modern architecture in the following order: Mies van der Rohe, Le Corbusier and Alvar Aalto. This sequence was justified based on the evolutionary complexity of each architect language. The work was initially developed with the study and discussion of the works of excellence of each one in seminar. Subsequently gave the construction of cardboard architectural models that should represent spaces of contemplation and pass, without specific use.

KEY-WORDS: modern architecture, design strategies; composition, project teaching.

\section{INTRODUÇÃO}

O tema desenvolvido nesse artigo faz parte da abordagem adotada pela disciplina de 'Estudos da Forma', que procura erigir um conhecimento relativo às questões morfológicas e compositivas, com ênfase em linguagens arquitetônicas modernas e contemporâneas, introduzindo assim o aluno no universo da Arquitetura por ensaios de estratégias compositivas. A construção do conhecimento relativo à área de projeto, desde o primeiro ano do curso, nos parece muito importante para ser, por vezes, negligenciada com temas excessivamente abstratos ou distantes do âmbito específico da arquitetura. Levando em conta esta afirmativa, e tendo como objeto a produção de maquetes de estudo em papelão, o trabalho teve como meta inserir os alunos iniciantes do curso de arquitetura em um exercício promotor para o entendimento da linguagem da obra de três grandes nomes da primeira geração de arquitetos modernos: Mies van der Rohe, Le Corbusier e Alvar Aalto. A atividade se desenvolveu em três momentos, cada um referente ao estudo e debate da obra de um arquiteto e sua posterior concretização de ensaios projetuais em maquetes físicas.

\section{SOBRE A RELEVÂNCIA DO ESTUDO DA PRIMEIRA GERAÇÃO DE MODERNOS}

Para grande parte dos autores da história da arquitetura, os arquitetos Mies van der Rohe, Le Corbusier, Alvar Aalto e Frank Lloyd Wright são notoriamente elencados como os quatro grandes formadores da linguagem atualmente utilizada. Sua importância histórica se baseia principalmente no fato de todos, cada um a seu modo, terem produzido uma linguagem arquitetônica apreensível, às vezes de maneira quase didática (1), 
que foi posteriormente incorporada, transformada e desmembradas em novas versões, produzindo um vasto universo de reverberações nas gerações posteriores e chegando, por fim, à produção contemporânea. O arquiteto Frank Lloyd Wright, não menos importante, foi propositalmente deixado de lado, por ter sabidamente produzido uma arquitetura de cunho regional, mais ligada às raízes culturais indígenas norte americanas, o que dificulta uma pouco a sua replicação e adaptação em outras culturas e contextos. Os outros três, entretanto, conseguiram criar regras de abrangência mais universal, que permitem através de adaptações e transformações construir novas linguagens e se inserir nos mais diversos contextos sócios culturais contemporâneos.

\section{Mies e a relação entre interior e exterior}

Mies van der Rohe foi, muito provavelmente, entre os arquitetos modernos, o mais universal de todos. A herança trazida do pavilhão de Barcelona (1928) continua até hoje seduzindo arquitetos de todo o mundo. A madura e vigorosa relação espacial entre os planos horizontais e verticais e a potente continuidade visual entre o interior e exterior são alguns dos pontos chave que corroboram para a permanência do forte poder de influência de tal edifício para a arquitetura mundial e seu consequente valor no ensino de projeto, desde o início do curso. Além do pavilhão de Barcelona, fizeram parte da pesquisa a casa Tugendhat (1928) e a casa Farnsworth (1939). Alguns alunos tiveram contato com o livro de Werner Blaser (Mies meets West), o que contribuiu para revelar a nítida analogia visual, belamente ilustrada em fotos, entre os sofisticados detalhes da arquitetura oriental japonesa e a obra de Mies, em uma rica transmutação do conhecimento através dos tempos.

\section{A caixa cubista de Corbusier}

Le Corbusier e sua clássica cartilha contendo os cinco pontos da arquitetura moderna foi o que mais escreveu e divulgou seu trabalho, tanto em termos de manifestos utópicos quanto de postulados pragmático teóricos, por fim chegando também a complexas regras de proporção regidas pelo sistema Modulor. Por tudo isso, é tido com um dos mais didáticos em termos de aprendizado e ensino. Seus cinco pontos ainda são amplamente utilizados em edifícios contemporâneos. Para citar um exemplo nacional, na primeira fase da obra de Oscar Niemeyer, fica nítido a influência corbuseriana, explícita no conjunto de edifícios da Pampulha (1942-44). As casas Savoye (1928), Stein (1926), Shodhan (1951), e Curutchet (1949) fizeram parte das obras mais estudadas do arquiteto. A caixa retangular de estudadas proporções e seus espaços internos de apelo cubista foram a tônica desta fase.

Os alunos perceberam um aumento significativo na complexidade espacial vinculada a obra de Corbusier, primordialmente pela liberdade com que o arquiteto desenvolve os espaços internos de modo independente da estrutura. Aqui se inicia por parte dos alunos a percepção do diálogo entre formas cartesianas, definidas pela caixa contenedora, e as formas livres, representadas pelos volumes e espaços internos.

\section{A polivalência maneirista de Aalto}

Por último, foi estudada a obra do arquiteto finlandês Alvar Aalto, dada sua alta complexidade. Aalto deixou poucos escritos que ajudassem no entendimento de sua linguagem. Ainda pouco se escreveu sobre Aalto sob o aspecto dos sistemas formais adotados e a lógica daí nascida. Sua arquitetura atinge um altíssimo grau de enredamento, mas nem por isso, deve deixar de ser pesquisada e compreendida. A vila Mairea (1938) foi utilizada como a grande referência do arquiteto, obra que revela um vasto jogo entre formas paralelipédicas alternadas por momentos de sinuosidade entremeados por um vasto e sinestésico leque de texturas, padrões geométricos e detalhes especiais. Outras obras relevantes estudadas foram a prefeitura de Säynätsalo (1949) e a casa de Muuratsalo (1952), ambas utilizando o tijolo como matéria prima, de um modo sábio e criativo, remetendo a certa ancestralidade arquitetônica. O aprendizado da obra de Aalto, embora pouco difundido, é a nosso ver de extrema importância para o entendimento de uma linguagem arquitetônica que busca se adaptar as particularidades de cada contexto, respeitando e incorporando de forma rica, livre e inserida na tradição construtiva local, se valendo de materiais naturais como a madeira, os tijolos em suas inúmeras nuances de tamanhos e tons e as pedras. Grande parte dos alunos se identificou mais com a obra de Aalto, fato este percebido pela comprovação de um menor grau de abstração da linguagem e pelo 
visível vínculo com a cultural local da Finlândia, focado primordialmente na boa utilização dos materiais naturais, que assim como a cultura nórdica, talvez sejam indicativos de um caminho mais adequado para a produção de uma arquitetura localizada no sul do Brasil. As estratégias compositivas utilizadas por Aalto, que incorporam adições, subtrações, junções, aglutinações e sobreposições, em um infinito, intrincado e complexo jogo espacial, liberaram aos alunos conhecer um novo leque de alternativas, ao mesmo tempo que se valer de certo afrouxamento de um rol de regras geométricas mais estritas impostas anteriormente quando da abordagem das obras de Mies e Corbusier.

O estudo da obra de Aalto consagrou sobremaneira o entendimento de uma arquitetura que extrapola a ideia de caixa (Mies e Corbusier), se valendo do domínio apurado da relação entre formas livres e cartesianas, conciliando volumes que revelam diferentes escalas conseguidas tanto pelo jogo de massas quanto pelo fino ajuste no tratamento das superfícies, em que a sábia utilização dos materiais acontece de maneira a criar detalhes singulares e consagrar o forte apelo à tatilidade presente na obra do arquiteto.

\footnotetext{
A superficialidade da construção padrão de hoje é reforçada por um senso enfraquecido de materialidade. Os materiais naturais-pedra, tijolo e madeira-deixam nossa que nossa visão penetre em suas superfícies e permitem que nos convençamos da veracidade da matéria. Os materiais naturais expressam sua idade e história, além de nos contar suas origens e seu histórico de uso pelos humanos (PALLASMAA, 2011, p.30).
}

\section{A IMPORTÂNCIA DA MAQUETE NO PROCESSO DE PROJETO}

Toda vez que temos notícia ou visitamos exposições sobre a obra de determinados arquitetos europeus, nos deparamos com uma plêiade de maquetes de todos os tipos e escalas. Algumas são definitivas e mostram o edifício no todo, construídas na fase final do anteprojeto, ricas em detalhes, outras, são de estudo, feitas como ensaios volumétricos iniciais de massa e servem para principiar a modelagem de uma forma específica, que geralmente acaba sofrendo alterações significativas ao longo do processo. A produção dos arquitetos suíços Herzog e de Meuron é um bom exemplo da utilização de maquetes no processo de projeto. A extensão da Tate modern em Londres, projeto de 2005 e recentemente inaugurada é um bom exemplo do papel da maquete no processo de desenvolvimento de projeto do escritório. Uma maquete de massa carrega informações do entorno, possibilita e induz o diálogo com o lugar. Em outro momento, maquetes individuais ilustram experimentos formais do edifício em si, independente do contexto, são investigações sobre materiais e tratamento de superfície, bem como escalas e proporções, em um total de 14 maquetes em escala reduzida. Percebe-se que nestas maquetes individuais já está definida uma estratégia morfológica geral e elas representam variações sobre o tema. O escritório suíço também tem por hábito, para determinadas obras, realizar mockups em escala real de determinado detalhe do edifício.

Explorar diferentes tipos de luminosidade e privacidade é o que mostram alguns estudos de maquete do arquiteto suíço Christian Kerez numa casa em Zurich (2004-2007), onde a maquete construída em escala de detalhe (geralmente 1:20, 1:25) permite visualizar os espaços internos contemplados com mobiliário e escala humana. São 04 alternativas de fechamentos horizontais que implicam em diferentes percepções do espaço interno. Nesta escala, boa parte dos detalhes fica aparente, e não há como ignorar os problemas de projeto que daí venham, forçando naturalmente a busca por melhores alternativas, a serem solucionadas na própria maquete, processo este, que se feito somente em desenho, não se completa de modo efetivo.

Outro atelier que faz tremendo sucesso entre a comunidade de arquitetos e estudantes, quando se trata do quesito maquete, é o escritório do holandês Rem Koolhaas (OMA). Infinitas maquetes de estudo são confeccionadas a cada novo desafio de projeto, explorando uma variada gama de possibilidades formais e programáticas, por vezes contraditórias entre si, mas repletas de potencialidades latentes.

Boa parte dos ateliers europeus, dos mais conhecidos e renomados internacionalmente até os de menor escala de produção, mas nem por isso de qualidade inferior, tem por hábito a boa utilização da maquete como poderosa ferramenta do processo de projeto, estabelecendo uma tradição de modelar o edifício em suas variadas escalas perceptivas, configurando uma maturidade agregada ao produto final, que culmina, por fim, em qualidades espaciais presentes nos edifícios construídos. 


\section{O PROCESSO DE TRABALHO}

O exercício acadêmico teve a duração de três meses, divididos em três módulos de um mês, cada um correspondendo a um arquiteto. No primeiro mês o arquiteto de referência foi Mies van der Rohe, no segundo, Le Corbusier e, no terceiro, Alvar Aalto. A escolha desta sequência foi definida pelo grau de dificuldade da percepção das formas relacionadas ao repertório dos diferentes arquitetos. Entendemos, por exemplo, que as características formais de Mies são mais facilmente compreendidas em comparação a Le Corbusier ou Aalto, no que se refere à clareza da forma, devido à sua característica clássica, associada à ortogonalidade, racionalidade e pureza formal, que se traduz no conjunto da obra.

Para cada arquiteto, equipes formadas por três alunos fizeram uma breve pesquisa sobre uma obra específica, definida antecipadamente pelos professores, e a apresentaram à turma em Power Point. Esta pesquisa inicial deveria contemplar principalmente o reconhecimento das qualidades estéticas, técnicas e espaciais das obras destes arquitetos, servindo de estímulo ao desenvolvimento do trabalho.

Mais intensa no início, a pesquisa perdurou até a última etapa. Em se tratando de alunos do primeiro ano do Curso, faltava-Ihes a bagagem de conhecimento relativo aos espaços e formas arquitetônicas, o que justificou um ir-e-vir entre pesquisa e prática no ateliê. Isto permitiu a superação do aluno, ainda que respeitando seu tempo de aprendizado, da sua visão inicial, caótica, sincrética sobre o objeto do conhecimento que é, neste caso, o aprendizado do projetar em arquitetura de forma mais abrangente, e as noções das estratégias compositivas mais especificamente. Como no dizer de Saviani (1985) cabe ao professor mediar este caminho da síncrese à síntese. Por isso, justamente, surge a necessidade do professor orientar, para esse trabalho, a respeito de um conhecimento relevante sobre a obra de arquitetos de referencia. Os alunos principiantes não tinham como saber quais obras contém valores arquitetônicos que merecem destaque para sua formação.

Na sequencia, a equipe deu início à elaboração do projeto denominado "Espaços de Passagem", por meio de desenhos e maquetes de papelão, contendo, como prerrogativa, algumas das características formais do arquiteto em estudo. A primeira entrega do trabalho relacionado a cada arquiteto caracterizou-se como uma pré-entrega, na forma de uma maquete de estudos, na mesma escala definida para a entrega final (1:20), contemplando a principal ideia do projeto, espaços, acessos, aberturas e elementos arquitetônicos (Figuras 1, 2, 3).

Figura 1 - O conjunto das Maquetes

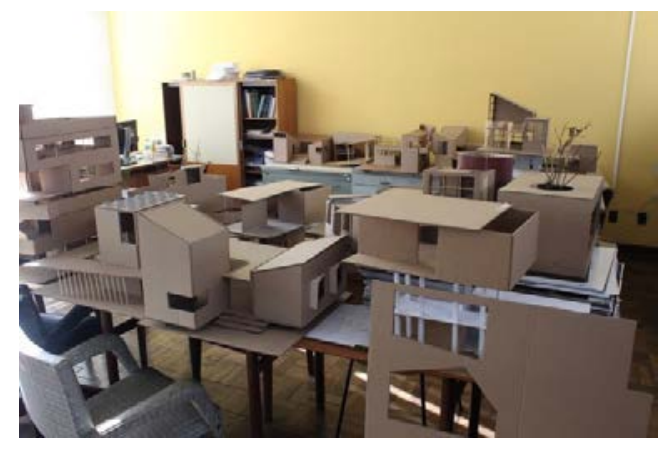

Fonte: Autor, 2016

Figura 2 - Maquete de estudo (Corbusier)

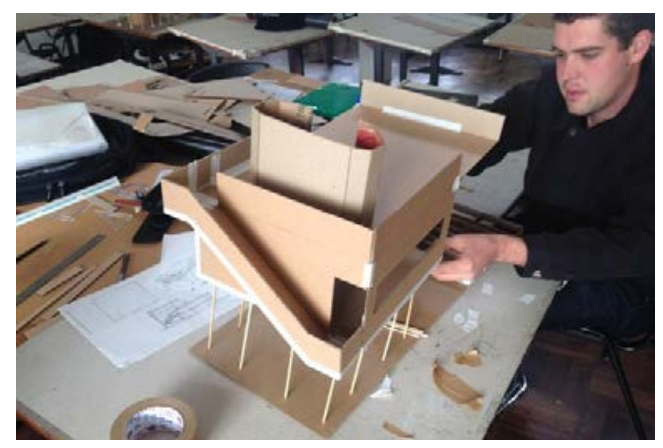

Fonte: Autor, 2016
Figura 3 - Maquete de estudo (Corbusier)

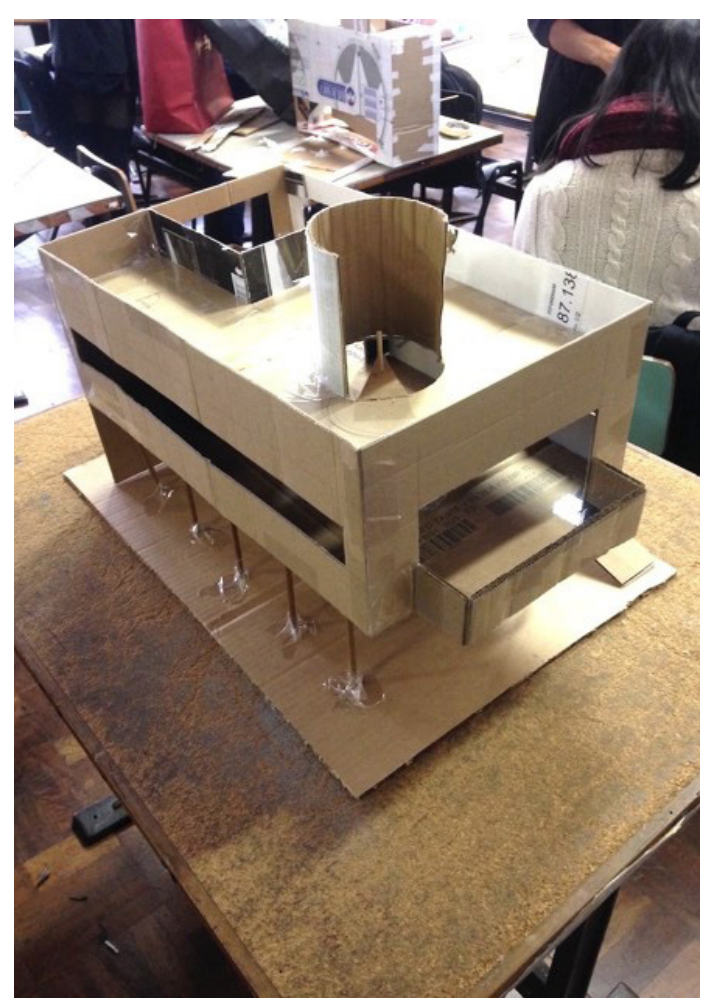

Fonte: Autor, 2016 
Como resultado final, as equipes entregaram também uma maquete em papelão como material principal. Detalhes, eventualmente poderiam ser feitos em outros materiais.

Os projetos cuja referência foi o arquiteto Mies Van der Rohe (Figuras 4, 5, 6) resultaram em formas mais simples, compostas de planos verticais e horizontais, ortogonais entre si, colunas, espelhos d'água e eventuais degraus de acesso para um nível térreo elevado (piano nobile). O sistema proposto por Mies, definido a partir da sábia relação geométrica entre planos verticais e horizontais e a integração entre o interior e exterior, se mostrou bastante compreensível por parte dos alunos, onde a obra de referência preferida foi o pavilhão de Barcelona, que gerou inúmeras variações sobre o tema. O discurso sobre a rica palheta de materiais utilizado por Mies no pavilhão foi citado, mas não aplicado ao tema, o que demandaria uma etapa posterior.

Com Le Corbusier (Figuras 7, 8, 9) como referência (segundo módulo), os projetos aumentaram em complexidade. Os alunos buscaram um entendimento dos cinco pontos da arquitetura, amplamente discutido em sala e, posto isto, as referências utilizadas se dividiram entre um grupo de obras anteriores aos anos 50 (Savoye, Stein), que definem uma arquitetura paralelipédica em forma de caixa, e um grupo de obras posteriores (Shodhan, Curutchet), fase de maior liberdade formal do arquiteto. O resultado desta etapa criou formas paralelepipédicas do edifício, em composições subtrativas, cujos espaços internos, em dois pisos, eram interligados por rampas e/ou escadas, contendo janelas em fita, sacadas, terraços-jardim, pilotis, cobogós e pérgolas. Vale ressaltar que poucos alunos conseguiram captar a complexidade do espaço interno Corbuseriano, se atendo mais a composição externa da caixa.

O terceiro módulo, tendo como referência a obra de Alvar Aalto (Figuras 10, 11, 12), chegamos, em termos de soluções formais, ao maior patamar de complexidade do exercício. Da prefeitura de Säynätsalo, os alunos tiraram como repertório formal, o jogo de volumes em diferentes escalas, enfatizando a torre do salão de atos, bem como o trabalho das aberturas, em suas ricas nuances de escalonamentos e ritmos. Surpreendentemente, a vila Mairea foi a obra mais elogiada, a menos compreendida e a menos utilizada como referência. Entendemos isto como uma maior dificuldade de compreensão de uma volumetria de maior de complexidade, com formas puras e livres sobrepostas somadas a abundante e pujante quantidade de detalhes especiais que acontecem a todo momento. Das casas Muuratsalo e Carré, veio a tona a ideia do pátio e de volumes com águas inclinadas. Alguns trabalhos comtemplaram a intenção de elaborar o desenho dos fechamentos e esquadrias com elementos verticais em madeira, abstrações do detalhe da escada da vila Mairea.

Figura 5 - Maquete final (Mies)

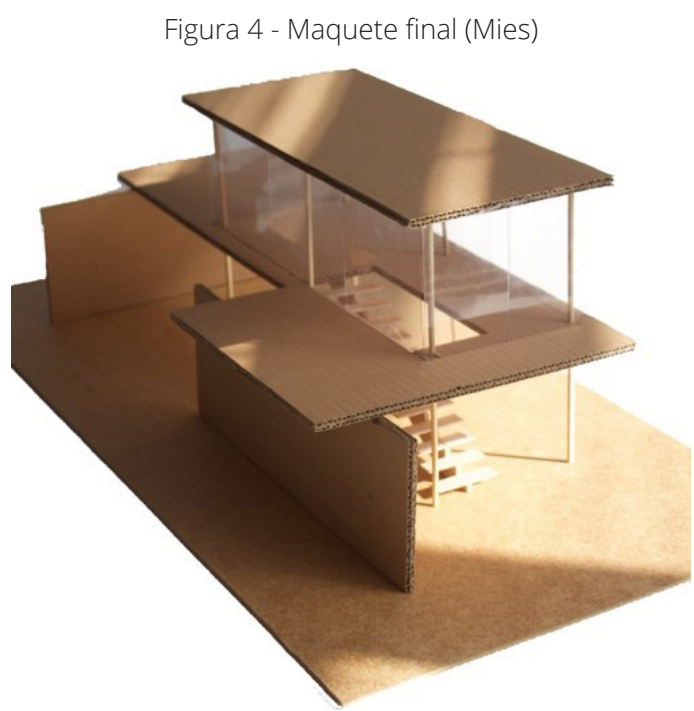

Fonte: Autor, 2016

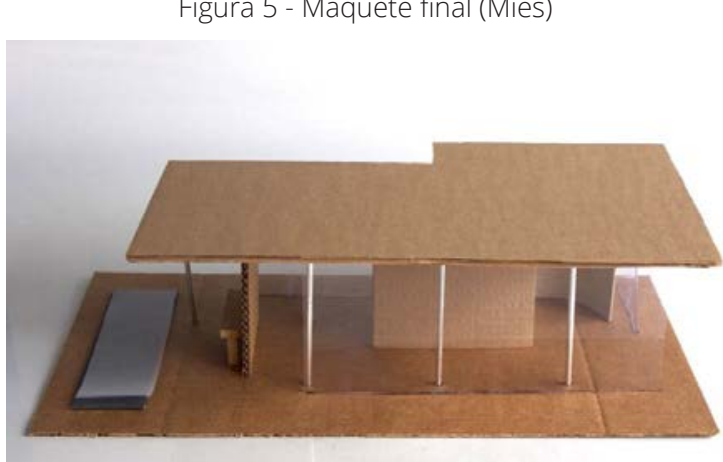

Fonte: Autor, 2016

Figura 6 - Maquete final (Mies)

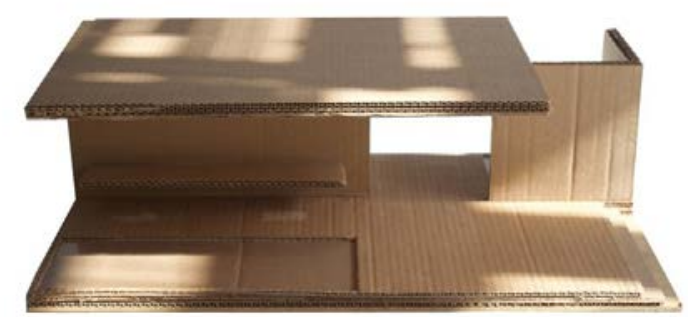

Fonte: Autor, 2016 
Figura 7 - Maquete final (Corbusier)

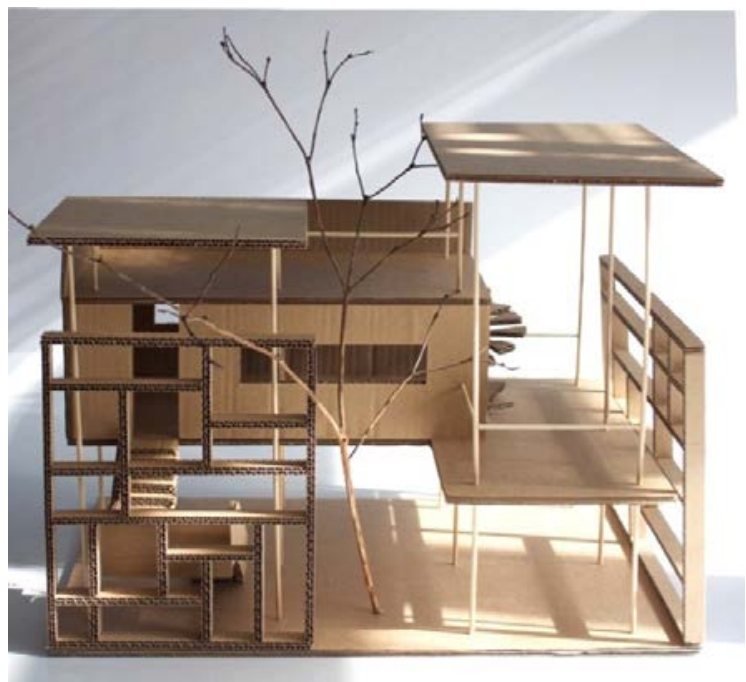

Fonte: Autor, 2016

Figura 10 - Maquete final (Aalto)

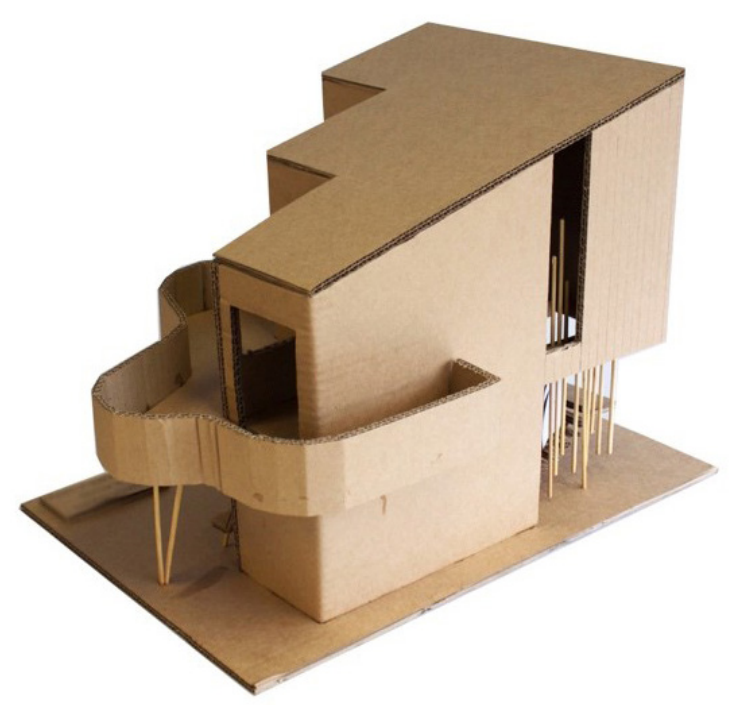

Fonte: Autor, 2016
Figura 8 - Maquete final (Corbusier)

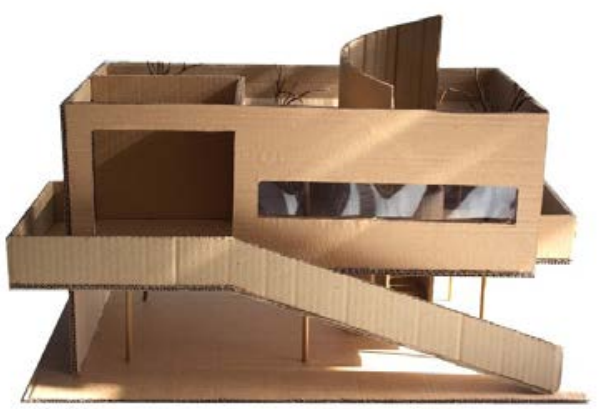

Fonte: Autor, 2016

Figura 9 - Maquete final (Corbusier)

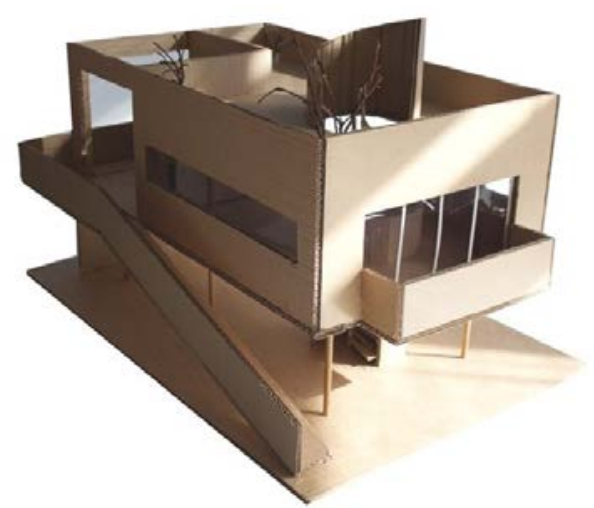

Fonte: Autor, 2016

Figura 11 - Maquete final (Aalto)

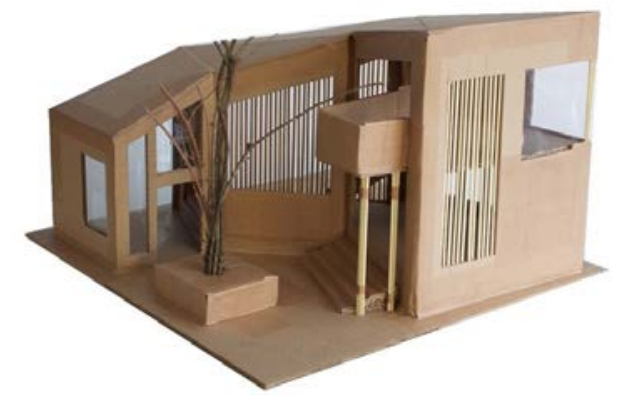

Fonte: Autor, 2016

Figura 12 - Maquete final (Aalto)

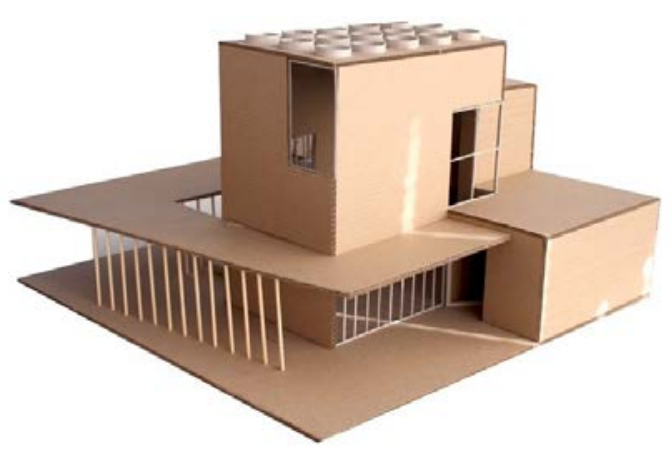

Fonte: Autor, 2016 
Como conteúdo de fundamentação da área de projeto, este exercício auxiliou na formação da imagem mental, no pensamento abstrato e na memória da realidade concreta. À medida que os alunos realizavam desenhos e maquetes, foram reveladas qualidades e relações não imaginadas de antemão, e, entre erros e acertos de projeto, desenvolveram competências e capacidades de avaliação sobre seu próprio objeto de estudo. Este é o caso, explica SCHÖN, no qual a prática "assemelha-se à pesquisa, sua investigação é uma transação com a situação, na qual conhecer e fazer são inseparáveis. A prática, assim, não é apenas uma complementação do processo de ensino-aprendizagem" (2000, p. 70).

Entre certa ingenuidade no desenho de formas e espaços e uma crescente criticidade na forma de se compreender a arquitetura, encontra-se a prática de uma educação que extrapola o conhecimento puramente técnico e busca a essência do caráter formador:

Como inquietação indagadora, como inclinação ao desvelamento de algo, como pergunta verbalizada ou não, como procura de esclarecimento, como sinal de atenção que sugere alerta e faz parte integrante do fenômeno vital. Não haveria criatividade sem a curiosidade que nos move e que nos põe pacientemente impacientes diante do mundo que não fizemos, acrescentando a ele algo que fazemos (FREIRE, 1996, p. 35).

A reflexão crítica das equipes, sobre os projetos que foram sendo criados, possibilitaram configurar o processo didático como uma ação interativa entre os professores e os alunos, permitindo que estes "aprendessem a aprender" (MARTINS, 2006, p98), mobilizando suas próprias capacidades cognitivas e afetivas para compreender, controlar e decidir minimamente sua aprendizagem. Além de se pretender desenvolver o conhecimento de estratégias compositivas e o estudo das formas e espaços em arquitetura, o verdadeiro desafio consistiu na abstração, que se efetivou ao se conceber noções e princípios, associar ideias e deduzir consequências independentemente do modelo ou exemplo estudado. Isto significa compreender um possível método para os próximos desafios em projeto e dar mais um passo em relação à formação do estudante de arquitetura.

Assim, as atividades didáticas relacionadas a esse exercício se transformaram em oportunidades de aprendizagem na medida em que:

- Transformaram a prática numa forma de pesquisa, na qual o desenho e a elaboração de maquetes foram um meio de criar espaços e formas, investigar um problema proposto, desenvolver um pensamento e disciplinar o processo;

- Carregaram consigo um claro conceito sobre o tipo de espaço específico a ser estudado através de referências de arquitetos importantes na história da arquitetura, vistos, neste trabalho, por suas características formais relevantes;

- $\quad$ Respeitaram o tempo de aprendizagem do aluno, considerando a complexidade psicológica e afetiva do desenvolvimento humano.

\section{CONSIDERAÇÕES FINAIS}

O resultado obtido no trabalho comprova duas teses: a primeira, é relativa à questão fabril da arquitetura, do manuseio do objeto arquitetônico físico, representado aqui pela maquete. A resposta dos alunos em termos de rapidez e eficiência do desenvolvimento do processo da construção das maquetes de papelão foi significativamente superior quando comparado ao trabalho feito somente com croquis ou desenhos realizados em computador. A escala escolhida para a maquete, 1:20, traz consigo informação suficiente para enxergar o espaço interno e até mesmo incorporar alguns eventuais detalhes. Nesta escala ficou claro para os alunos enxergar o papel da busca pela boa composição, da proporção adequada e da forma concisa. Os erros e acertos ficam muito mais visíveis em maquetes de grande porte e não há como esconder algo que deve ser aprimorado.

A tradição do desenvolvimento de projeto utilizando maquetes de estudos é uma prática comum em muitos escritórios de arquitetura europeus. No Brasil, todavia, até pouco tempo o ensino ainda priorizava as questões do desenho em prol da maquete física. Isto se justifica em parte pela composição do corpo docente, que era em sua maioria constituído de profissionais que atuavam diretamente no mercado, mas não tinham formação acadêmica mais elevada. Desta forma, o foco recaía de modo incisivo sobre a questão da boa resolução do 
programa, induzindo a uma discussão do projeto em planta, ou seja, bidimensionalmente. Não é por acaso que boa parte da arquitetura moderna brasileira se resume na resolução de espaço interno em forma de caixa absoluta, o que a empobrece sobremaneira. Como exemplo não tão distante, o arquiteto conterrâneo português Álvaro Siza comtempla um processo de trabalho que se desenvolve em maquetes e desenhos, estes em grande parte perspectivas do observador inserido no espaço. O resultado é uma arquitetura rica e complexa espacialmente, que se afasta de uma excessiva planaridade, por vezes resultado de um descomedido rigor na manipulação de diagramas e esquemas estruturais preconcebidos, que acabam enrijecendo o desenvolvimento do processo de projeto e castrando a apropriação de um universo de possibilidades mais amplo.

A segunda tese é a de que o emprego de boas referências pode gerar bons projetos. O fato de estudar, discutir e exercitar a linguagem presente na obra de arquitetos de excelência, de forma prática, dá aos alunos um real entendimento do conjunto e da lógica imanente presentes em cada um, desenvolvendo de forma concreta e enraizada um repertório arquitetônico essencial para alunos em início de curso. Percebemos, ao final do exercício, a importância de utilizar como âncoras, obras compreendidas não apenas no período que vai do final do sec. XIX ao início do séc. XX, recorte comumente utilizado quando se trata do ensino das vanguardas, mas de cunhar também uma visão panorâmica mais abrangente em termos da historia da arquitetura e das lições que dela podemos extrair.

Relembrando as palavras de Aldo Rossi:

Também por isso todas as grandes arquiteturas se repropõe a arquitetura da antiguidade, como se a relação fosse fixada para sempre; mas cada vez se repropõe como uma individualidade diferente (Rossi, 1995, p.52).

Resgatar o entendimento da essência de arquiteturas anteriores ao período moderno pode ser um caminho a ser seguido, tanto no sentido de uma formação mais sólida e universalmente abrangente, quanto de uma reflexão crítica sobre determinados estereótipos e mitos, por vezes negativamente solidificados na academia.

\section{REFERÊNCIAS}

AALTO, A.; CIRLOT, J. E.; CIRLOT, L. Aalvar Aalto. Barcelona: G. Gili, [C1961].

BAKER, G. Le Corbusier: analisis de la forma. 5. ed. ampliada. Barcelona: G.Gili, 1994

BLASER, W. Mies van der Rohe. 2. ed. São Paulo: Martins Fontes, 2001.

BLASER, W. West meets east, Mies van der Rohe. Basel: Birkhauser, 2001.

FREIRE. P. Pedagogia da autonomia: saberes necessários à prática educativa. São Paulo: Paz e Terra, 1996.

LE CORBUSIER et al. Le Corbusier et Pierre Jeanneret, oeuvre complète. Basel: Birkhauser, 1999, c1995.

MARTINS, P. L. O. As formas e práticas de interação entre professores e alunos. In: VEIGA, I. P. A. (Org.). Lições de didática Campinas: Papirus, 2006, pp.75-100.

PALLASMAA, J. Os olhos da pele: a arquitetura e os sentidos. Tradução técnica Alexandre Salvaterra. Porto Alegre: Bookman, 2011.

ROSSI, A. A arquitetura da cidade. Tradução: Eduardo Brandão. São Paulo, Martins Fontes, 1995.

SAVIANI, D. Educação: do senso comum à consciência filosófica. São Paulo: Cortez/Ed. Autores Associados, 1980.

SCHILDT, G. Alvar Aalto, obra completa: arquitectura, arte y diseno. Barcelona: G. Gili, c1994.

SCHÖN, D. A. Educando o profissional reflexivo: um novo design para o ensino e a aprendizagem. Trad.: Roberto Cataldo Costa.

Porto alegre: Artes médicas Sul, 2000.

WESTON, R. Alvar Aalto. London: Phaidon, 1995.

\section{NOTAS}

(1) Os cinco pontos da arquitetura de Le Corbusier são um bom exemplo.

NOTA DO EDITOR (*) O conteúdo do artigo e as imagens nele publicadas são de responsabilidade do(s) autor(es). 